\title{
YEAST CHITIN SYNTHASE 2 ACTIVITY IS MODULATED BY PROTEOLYSIS AND PHOSPHORYLATION
}

Fuensanta W. Martínez-Rucobo, Luise Eckhardt-Strelau and Anke C. Terwisscha van Scheltinga*

Max Planck Institute of Biophysics, Department of Structural Biology, Max-von-Laue-Str. 3, D-60438 Frankfurt am Main, Germany

Running title: Characterization and regulation of yeast chitin synthase 2

Keywords: chitin synthase, overexpression, regulation, posttranslational modification, proteolytic activation, phosphorylation

*Address correspondence to: Anke C. Terwisscha van Scheltinga, Max Planck Institute of Biophysics, Department of Structural Biology, Max-von-Laue-Strasse 3, D-60438 Frankfurt am Main, Germany. Fax +49 69 63033002; E-mail anke.terwisscha@mpibpfrankfurt.mpg.de 
Saccharomyces cerevisiae chitin synthase 2 (Chs2) synthesizes the primary septum after mitosis is completed. It is essential for proper cell separation and expected to be highly regulated. We have expressed Chs 2 and a mutant lacking the $\mathrm{N}$-terminal region in Pichia pastoris in an active form at high levels. Both constructs show a pH and cation dependence similar to the wild-type enzyme, as well as increased activity after trypsin treatment. Using further biochemical analysis, we have identified two mechanisms of chitin synthase regulation. First, it is hyperactivated by a soluble yeast protease. This protease is expressed during logarithmic growth phase, when budding cells require Chs 2 activity. Secondly, LCMS/MS experiments on purified Chs2 identify twelve phosphorylation sites, all in the N-terminal domain. Four of them show the perfect sequence motif for phosphorylation by the cyclin-dependent kinase Cdk1. As we also show that phosphorylation of the $\mathrm{N}$-terminal domain is important for Chs2 stability, these sites might play an important role in the cell cycle-dependent degradation of the enzyme, and thus in cell division.

Chitin, a $\beta$-1,4-linked polymer of $N$-acetylglucosamine, is a polysaccharide that has an important structural role in many organisms, such as arthropods, molluscs, cephalopods, and fungi. The amounts of chitin present vary between these organisms; in yeast it constitutes only one percent of the cell wall, but still is an essential component [1, 2]. Chitin is synthesized from UDP-GlcNAc by chitin synthases (EC 2.4.1.16). Typically, these enzymes consist of three domains [3]: a hydrophilic amino-terminal domain, a highly conserved central catalytic domain and a hydrophobic carboxy-terminal domain integrated into the membrane (Fig. 1). Chitin synthases are classified into glycosyl transferase family $2[4,5]$, a sequence family that contains a wide range of enzymes. Besides chitin synthases, the most notable examples are the synthases of the structural polysaccharides cellulose, hyaluronan, $\beta-1,3$-glucan and $\beta$-1,4-mannan. The catalytic domains of the glycosyl transferase family 2 share a GT-A fold [6].

Saccharomyces cerevisiae contains three membrane-bound chitin synthases. Each enzyme has its own specific function. Chs1 has a repair function during cell separation [7], Chs2 is essential for primary septum formation and thus for cell division [8], and Chs3 synthesizes the chitin ring at bud emergence, as well as the chitin in the cell wall [2]. Since each chitin synthase acts at a different stage of the cell cycle, independent mechanisms for their regulation must exist in the cell. Disruption of specific chitin synthase genes also results in different effects. S. cerevisiae cells lacking Chs1 grow normally, without showing apparent loss of cell wall chitin content [9]. Likewise, disruption of the Chs 3 gene was not lethal [10]. Therefore, these enzymes do not seem to be critical for yeast cell survival. On the other hand, disruption of Chs2 causes severe growth defects and morphological abnormalities [11, 12]. The regulation of Chs2 is different from that of the other two: its concentration in the cell changes greatly during the cell cycle, in contrast to the constant levels of Chs1 and Chs3 [13-15]. So, whereas regulation of Chs 1 and Chs 3 can only be posttranslational, Chs2 is also significantly regulated by synthesis and degradation.

Chs2 is especially interesting as it shows $55 \%$ sequence identity and is functionally analogous to chitin synthase 1 from the human pathogen Candida albicans, which is essential for cell survival [12]. The importance of these enzymes for their organisms, together with the lack of chitin synthases in humans, makes them excellent targets for antifungal drugs. 
In this paper we report the heterologous expression and characterization of Chs2. As it had been previously shown that the N-terminal 222 amino acid residues of Chs2 could be truncated without loss of activity or function [16], we have also overexpressed the active mutant Chs $2 \Delta \mathrm{N} 222$. Biochemical characterization of both proteins allows further insights in Chs 2 regulation by posttranslational modification, as well as the role of the N-terminal domain.

\section{Experimental procedures}

Bacterial and yeast constructs. Genomic DNA from S. cerevisiae strain Y3437 was used for PCR amplification of the Chs 2 and Chs $2 \Delta \mathrm{N} 222$ genes.-The primers used for amplifying Chs2 were: 5'-ATTGCACATATGACGAGAAACCCGTTTATGGTGG-3' and 5'-TCCTCGAGGCCCTTTTTGTGGAAAACATTTG-3', containing NdeI and XhoI sites respectively (underlined). For amplification of Chs $2 \triangle N 222$ the primers were: $5^{\prime}-$ ATTGCACATATGGTCTCAGACTTGCCTCCC-3' and 5'-TCCTCGAGGCCCTTTTTGTGGAAAACATTTG-3', containing NdeI and XhoI sites respectively (underlined). For bacterial expression, the two constructs were inserted into the NdeI and XhoI sites of the pET26b vector (Novagen). For expression in P. pastoris, the constructs were cloned in a modified pPICZ B vector (Invitrogen) containing a Strep 2 tag, prescission cleavage site, multiple cloning site for NdeI and XhoI restriction sites, prescission cleavage site, and $\mathrm{His}_{10}$ tag; for this system expression is under the control of the alcohol oxidase (AOX1) promoter. All constructs contain a poly-histidine tag for protein detection by Western blot analysis. The correct insertion and sequence of each construct was confirmed by DNA sequencing.

$P$. pastoris culture conditions. The protease-deficient $P$. pastoris strain SMD1163 (Invitrogen) was used for expression of the recombinant genes. The higher expressing clones were selected according to [17] and made into $\mathrm{His}^{+}$mutants by transformation with a pPIC3.5 vector. For expression, SMD1163 cells carrying the foreign gene were grown overnight in MGY medium $(0.34 \%(\mathrm{w} / \mathrm{v})$ yeast nitrogen base, $1 \%(\mathrm{w} / \mathrm{v})$ ammonium sulphate, $1 \%(\mathrm{w} / \mathrm{v})$ glycerol, $4 \times 10^{-5} \%(\mathrm{w} / \mathrm{v})$ biotin) to an $\mathrm{OD}_{600} \mathrm{~nm}$ of 2-6. The cells were centrifuged at $1,500 \times \mathrm{g}$ for $10 \mathrm{~min}$, then suspended to an $\mathrm{OD}_{600}$ of 1-2 in MM $(0.34 \%(\mathrm{w} / \mathrm{v})$ yeast nitrogen base, $1 \%(\mathrm{w} / \mathrm{v})$ ammonium sulphate, $1.64 \mu \mathrm{M}$ biotin, $0.5 \%(\mathrm{v} / \mathrm{v})$ methanol) and grown for $24 \mathrm{~h}$ at $30{ }^{\circ} \mathrm{C}$. Cells were harvested by centrifugation at $1,500 \times \mathrm{g}$ for $10 \mathrm{~min}$ and the pellets stored at $-80{ }^{\circ} \mathrm{C}$ or used immediately for further studies.

P. pastoris membrane preparation. Cells were suspended to an $\mathrm{OD}_{600}$ of 50-100 in $30 \mathrm{mM}$ HEPES pH 7.5 and $100 \mathrm{mM} \mathrm{NaCl}$. After addition of an equal volume of ice-cold acid-washed glass beads $(0.5 \mathrm{~mm}$ diameter $)$, the cells were broken by vortex mixing for eight $30 \mathrm{~s}$ bursts separated by $30 \mathrm{~s}$ cooling on ice. Glass beads, cell debris and unbroken cells were removed by centrifugation at $1,500 \mathrm{x} g$ for $10 \mathrm{~min}$ and the pellet was washed with an equal volume of buffer and centrifuged again. To separate the membrane fraction from the soluble components, the combined supernatants were then centrifuged at $100,000 \times \mathrm{g}$ for $30 \mathrm{~min}$. The crude membrane pellet was suspended in $30 \mathrm{mM}$ Tris or HEPES buffer $\mathrm{pH} 7.0,7.5$ or 8.0 and the protein content determined using the DC protein assay (BioRad). 
Bacterial culture conditions. Chs 2 and Chs $2 \Delta \mathrm{N} 222$ were expressed in E. coli $\mathrm{C} 41$ (Avidis). Bacterial cells were grown at $37{ }^{\circ} \mathrm{C}$ in $\mathrm{TB}$ medium until $\mathrm{OD}_{600}$ reached 0.6-0.8, and then induced with $2 \mathrm{mM}$ IPTG for 3-5 h. Cells were harvested by centrifugation at $3,300 \mathrm{~g}$ for $15 \mathrm{~min}$ and used immediately for membrane preparation.

Bacterial membrane preparation. Cells were suspended in $30 \mathrm{mM}$ Tris $\mathrm{pH} 7.5$ and $150 \mathrm{mM} \mathrm{NaCl}$. The cells were then passed three times through a Microfluidiser model M-110L (Microfluidics Corp., Newton, MA) equipped with a $110 \mu \mathrm{M}$ interaction chamber and a cooling coil, which were immersed in water at $0{ }^{\circ} \mathrm{C}$. After centrifugation at $15,000 \mathrm{~g}$ for $10 \mathrm{~min}$, the supernatant was centrifuged at $100,000 \mathrm{~g}$ for one hour. The pellet was suspended in $30 \mathrm{mM}$ Tris $\mathrm{pH} \mathrm{7.5}$, and the protein content was determined as above.

S. cerevisiae culture conditions. S. cerevisiae wild type strain YPH419 were grown overnight in YPD medium $(1 \%(\mathrm{w} / \mathrm{v})$ yeast extract, $2 \%(\mathrm{w} / \mathrm{v})$ peptone, $2 \%(\mathrm{w} / \mathrm{v})$ dextrose) to $\mathrm{OD}_{600} 0.5$ (logarithmic phase) or to $\mathrm{OD}_{600} 14$ (stationary phase). The $P$. pastoris membrane preparation protocol was followed, and the supernatant of the 100,000 $\mathrm{x} g$ centrifugation step (soluble fraction) was stored at $-80^{\circ} \mathrm{C}$ or used immediately.

Activity assay. The assay for measuring chitin synthase activity was carried out according to a previously described method $[18,19]$ in a $50 \mu 1$ reaction mixture. Unless otherwise indicated, it contained $30 \mathrm{mM}$ Tris $\mathrm{pH} 7.5,5 \mathrm{mM} \mathrm{MgCl}_{2}$ (for Chs $2 \Delta \mathrm{N} 222$ ) or 5 $\mathrm{mM} \mathrm{MnCl}$ (for Chs2), $32 \mathrm{mM}$ GlcNAc, $1 \mathrm{mM}$ UDP-(U- ${ }^{14} \mathrm{C}$ )-GlcNAc (Amersham, specific activity $553,000 \mathrm{dpm} / \mu \mathrm{mol}$ ), and $25 \mu \mathrm{g}$ of $P$. pastoris or $800 \mu \mathrm{g}$ of E. coli membranes. For investigation of the activity at a pH range of 6 to 9, a mixture of buffers was used. This mixture contained $30 \mathrm{mM}$ HEPES, $30 \mathrm{mM}$ MES and 30mM TAPS. To test divalent cation specificity, $5 \mathrm{mM}$ of a cation salt $\left(\mathrm{MgCl}_{2}, \mathrm{MnCl}_{2}, \mathrm{CoCl}_{2}, \mathrm{NiCl}_{2}\right.$ or $\mathrm{CdCl}_{2}$ ) or $5 \mathrm{mM}$ EDTA was used in the reaction mixture. Samples where incubated at 30 ${ }^{\circ} \mathrm{C}$ for $30 \mathrm{~min}$ for $P$. pastoris, or 16 to $20 \mathrm{~h}$ for $E$. coli membranes. To measure background activity from the chitin synthases of $P$. pastoris, membranes that did not contain overexpressed chitin synthases were used. Mean values and errors (standard deviation) were calculated from two sets of three independent experiments, using the program OriginPro 7.5.

Chitin synthesis was stopped by the addition of $1 \mathrm{ml}$ of ice-cooled $10 \%$ trichloroacetic acid, and the insoluble chitin was collected by filtration through a GF/B glass-fibre disc (Whatman) previously soaked in $10 \%$ trichloroacetic acid. The filters were subsequently washed three times with $1 \mathrm{ml}$ ice-cooled $10 \%$ trichloroacetic acid, and twice with $1 \mathrm{ml}$ ice-cooled $66 \%$ ethanol, according to [20]. Filters were then transferred to scintillation fluid (Rotiscint eco plus, Roth). Synthesized chitin was quantified by determining the radiation level of the filter using a scintillation counter TRI-CARB 1500 (Canberra-Packard).

Proteolytic activation. For activation of Chs 2 and Chs $2 \Delta \mathrm{N} 222$ by trypsination, $P$. pastoris membranes were incubated with trypsin (Sigma-Aldrich) for $10 \mathrm{~min}$ at $30{ }^{\circ} \mathrm{C}$. As previously reported $[18,21]$, the optimal amount of trypsin needed to be ascertained for each batch of membranes. The optimal trypsin/total membranes ratio varied from 1:30 to 1:150. After the 10 min incubation, proteolysis was stopped by adding a two-fold excess 
of soybean trypsin inhibitor (Fluka).

To activate Chs 2 and Chs $2 \Delta \mathrm{N} 222$ using the soluble $S$. cerevisiae fraction, the soluble fraction was incubated with trypsin for $10 \mathrm{~min}$ at $30{ }^{\circ} \mathrm{C}$, after which a two-fold excess of trypsin inhibitor was added. This mixture was then added to the chitin synthaseexpressing membranes and incubated for $10 \mathrm{~min}$ at $30{ }^{\circ} \mathrm{C}$.

Inactivation of soluble $S$. cerevisiae fraction. The trypsin-activated soluble $S$. cerevisiae fraction was incubated with each of the following protease inhibitors: pefabloc $(100 \mu \mathrm{M})$, E-64 $(15 \mu \mathrm{M})$, leupeptin $(400 \mu \mathrm{M})$, benzamidin $(100 \mu \mathrm{M})$ and pepstatin A $(20$ $\mu \mathrm{M})$. After this, the mixture was added to Chs2-containing membranes and the activity assay was carried out.

Protein dephosphorylation. $100 \mu \mathrm{g}$ of $P$. pastoris membranes were incubated with 2 units of calf intestine alkaline phosphatase (Roche) for $16 \mathrm{~h}$ at $4{ }^{\circ} \mathrm{C}$.

Partial protein purification. P. pastoris membranes containing overexpressed Chs 2 were diluted in solubilization buffer $(200 \mathrm{mM} \mathrm{NaCl}, 30 \mathrm{mM}$ imidazole $\mathrm{pH} 7.5,10$ $\%$ glycerol (w/v), $1 \%$ Fos-choline-14) plus protease inhibitors $(0.1 \mathrm{mg} / \mathrm{ml}$ trypsin inhibitor, $1 \mathrm{mM}$ benzamidine, $0.1 \mathrm{mM}$ pefabloc) and incubated for one our at $4{ }^{\circ} \mathrm{C}$. The unsolubilized material was removed by centrifugation for one hour at $170,000 \mathrm{~g}$ and loaded onto a Ni-sepharose (Amersham) column. The column was washed with wash buffer (70 mM imidazole pH 7.5, $150 \mathrm{mM} \mathrm{NaCl}, 0.05 \%$ Fos-choline-14) and eluted with buffer containing $300 \mathrm{mM}$ imidazole $\mathrm{pH} 7.5,150 \mathrm{mM} \mathrm{NaCl}$ and $0.05 \%$ Fos-choline- 14.

SDS/PAGE: $10 \%$ resolving gels were prepared and overlaid with a $3 \%$ stacking gel. Before electrophoresis the proteins were denatured in sample buffer (60 mM Tris $\mathrm{pH}$ $6.8,1.5 \%$ SDS, $10 \%$ glycerol, $0.005 \%$ bromphenol blue, $50 \mathrm{mM}$ DTT).

Western blotting. After SDS/PAGE, proteins were transferred onto PVDF membrane (Immobilon ${ }^{\mathrm{TM}}$ pore size $0.45 \mu \mathrm{m}$, Millipore) using a semi-dry transfer apparatus (Trans-Blot ${ }^{\circledR} \mathrm{SD}, \mathrm{Bio}-\mathrm{Rad}$ ). For immuno-detection, proteins were probed with monoclonal anti-poly-histidine antibody (Sigma-Aldrich) and visualized with anti-mouse alkaline phosphatase-conjugated secondary antibody (Sigma-Aldrich), both antibodies were diluted $1: 1,000$ in $20 \mathrm{mM}$ Tris $\mathrm{pH} 7.5$ plus $150 \mathrm{mM} \mathrm{NaCl}$.

Phosphorylation site mapping. The partially purified protein was resolved by SDS/PAGE analysis and the gel fraction containing Chs2 was cut out for phosphopeptide mapping. This analysis was done at the Center for Functional Genomics (University at Albany, Rensselaer, NY). For this purpose, the protein was in-gel tryptic digested and the resulting phosphopeptides were enriched by $\mathrm{TiO}_{2}$ IMAC. LC-MS/MS was performed on the enriched fraction to identify phosphorylation sites, and on the entire sample to determine the sequence coverage.

Protein phosphorylation. $150 \mathrm{mg}$ of $P$. pastoris membranes were incubated with 20 units of $\mathrm{M}$ phase Cdc2-cyclin $\mathrm{B}$ (NEB, recognition motif S/TP-X-K/R) for $30 \mathrm{~min}$ at $30{ }^{\circ} \mathrm{C}$ in a $30 \mu 1$ reaction mixture containing $200 \mu \mathrm{M} \gamma-{ }^{32} \mathrm{P}-\mathrm{ATP}$ (Perkin-Elmer, 3 $\mathrm{mCi} / \mu \mathrm{mol})$ and protease inhibitors $(0.1 \mathrm{mg} / \mathrm{ml}$ trypsin inhibitor, $1 \mathrm{mM}$ benzamidine, 0.1 $\mathrm{mM}$ pefabloc). After SDS/PAGE, phosphorylated protein was detected by 
autoradiography.

\section{Results and discussion}

We established the heterologous expression of the $S$. cerevisiae Chs2 and the deletion mutant Chs $2 \Delta \mathrm{N} 222$ in P. pastoris and E. coli. To further study the proteins, we isolated membranes from both expression systems. As observed by immunodetection (Fig. 2), the proteins migrate on SDS/PAGE with the molecular weights expected from their amino acid sequences (115 and $90 \mathrm{kDa}$ for Chs2 and Chs $2 \Delta \mathrm{N} 222$, respectively, including affinity tags), showing that neither Chs 2 nor Chs $2 \Delta \mathrm{N} 222$ are glycosylated. This is consistent with a Chs $2 \Delta \mathrm{N} 193$ mutant expressed in S. cerevisia that was shown not to be glycosylated [22], and is further confirmed by the observation that the proteins expressed in E. coli, which lacks the glycosylation machinery of yeast, have molecular weights comparable to the P. pastoris-expressed proteins (Fig. 2).

Chs 2 and Chs $2 \Delta \mathrm{N} 222$ expressed in both expression systems are active. However, the activities of $E$. coli-expressed proteins were significantly lower than those from $P$. pastoris. Longer incubation time and higher amounts of membranes were needed to measure similar levels of activity. Therefore, for further characterization only the $P$. pastoris-expressed proteins were used. $P$. pastoris is a yeast with a chitinous cell wall like $S$. cerevisiae, and indeed, $P$. pastoris membranes not expressing Chs 2 show chitin synthase activity. This activity is, however, negligible compared to that of overexpressed Chs2 or Chs2 2 N222 (Fig. 3).

To determine whether both Chs 2 and Chs $2 \Delta \mathrm{N} 222$ show enzymatic characteristics similar to the wild-type protein, their dependence on both $\mathrm{pH}$ and divalent cations was investigated (Fig. 3). The P. pastoris-expressed Chs2 and Chs $2 \Delta \mathrm{N} 222$ activities are strictly dependent on divalent cations (Fig. 3b). For Chs2 we obtained the highest activity in the presence of $\mathrm{Mn}^{2+}$, and reduced activity with $\mathrm{Mg}^{2+}$ and $\mathrm{Co}^{2+}$. Chs $2 \Delta \mathrm{N} 222$ showed high activity in the presence of $\mathrm{Mn}^{2+}$ and $\mathrm{Mg}^{2+}$, with a slight preference for $\mathrm{Mg}^{2+}$, and, like the full-length protein, less activity with $\mathrm{Ni}^{2+}$ and $\mathrm{Co}^{2+}$. For all constructs, upon adding EDTA or $\mathrm{Cd}^{2+}$ to the reaction mixture activity was lost.

This preference for $\mathrm{Mn}^{2+}$ or $\mathrm{Mg}^{2+}$ fits with X-ray structures of glycosyl transferases with the GT-A fold, which show that either of these two cations bind the two phosphate groups of the UDP-sugar substrate, and are thought to assist in cleaving the sugar-UDP bond $[6,23]$. The decrease of activity using the various divalent cations matches the decrease of their ionic radii, and also corresponds with the cation selectivity of wild type Chs2 and S. cerevisiae-expressed mutants [18, 22].

Besides the cation dependence, our two constructs also share an optimum $\mathrm{pH}$ between 7.5 and 8.5 with the wild-type enzyme (Fig. 3a) [18, 24, 11, 22]. Together, these results show that in $P$. pastoris the protein is expressed in a functional form, having the characteristics of the wild type enzyme. Moreover, when treated with appropriate amounts of trypsin, both proteins show high levels of hyperactivation (Fig. 4); this too is consistent with the wild type enzyme $[18,16]$. Interestingly, the two proteins exhibit different levels of proteolytic hyperactivation: 18-fold for Chs $2 \Delta \mathrm{N} 222 v s$. 6-fold for Chs 2 (Fig. 4). The increased activation level for Chs $2 \Delta \mathrm{N} 222$ as compared to Chs 2 implies that 
the N-terminal domain obstructs trypsin activity, and that its removal could lead to a more exposed activation site.

\section{Regulation of Chs2}

Chs2 synthesizes the primary septum separating mother and daughter cell after contraction of the acto-myosin ring $[25,26]$, at a very specific time and position. This requires strong regulation of Chs2 activity. Most obviously, the expression and degradation of the enzyme are under tight control, resulting in a half-life of only 25 minutes [14]. Although the expression of Chs2 peaks during mitosis [13], the protein accumulates in the endoplasmic reticulum until mitotic exit, when it is transported to the mother-bud neck [27]. It already disappears from the neck eight minutes later [28, 27], to be degraded by the major vacuolar protease PEP4 [14].

In addition to this metabolic regulation, post-translational modification has been observed for Chs2. Chs2 is phosphorylated in vitro by, and thus a possible in vivo target of, the cyclin-dependent kinase Cdk1 in complex with the mitotic phase cyclin Clb2 [29, 30]. Also, the in vitro chitin synthase activity is increased markedly by proteolysis [18].

\section{Proteolytic activation}

There is a long-standing question about the putative zymogenic form of chitin synthases. For $S$. cerevisiae, the three chitin synthases are active in their unprocessed form. Trypsin has been reported to stimulate chitin synthase activity of Chs1 and Chs2 [31, 18], but not of Chs3 [24]. In the case of Chs1, the stimulation was 7- to 15-fold [31, 18], trypsin treatment of Chs 2 shows around four times increased activity [18]. In the case of the insect $M$. sexta, trypsin does not actiyate chitin synthesis directly. However, trypsin was found to activate a soluble stimulatory factor in the midgut, which increased chitin synthesis by 25-30\% [32]. For our P. pastoris-expressed constructs, we measured 6 times activation by trypsination for the full-length protein, and 18 times for the $\mathrm{N}$ terminal deletion mutant (Fig. 4, panel 6).

Even though hyperactivation by proteolysis has been well established for Chs1 and Chs2, no endogenous protease that could take this role has been identified. Chs1 was reported to be activated by $S$. cerevisiae proteinase B [31,33]. However, proteinase B did not influence Chs1 activity in vivo [34, 35], demonstrating that either the observed proteolytic stimulation is not physiologically relevant, or performed by another protease.

We tested the possibility of hyperactivation of Chs2 by factors present in the soluble fraction of $S$. cerevisiae cells, using cells with a logarithmic growth rate, harvested at an $\mathrm{OD}_{600}$ of 0.5 . We found that incubation with the soluble fraction of $S$. cerevisiae cells in itself does not influence Chs 2 activity in P. pastoris membranes. However, when the soluble fraction is first treated with trypsin, and then after inhibition of trypsin is added to the $P$. pastoris membranes, it does increase Chs 2 and Chs $2 \Delta \mathrm{N} 22$ activity two-to four-fold (Fig. 4, panel 3).

A number of controls were necessary to confirm that indeed there was an activating factor in the soluble fraction. First, the trypsin-activated soluble fraction did not show any chitin synthase activity by itself (Fig. 4, panel 4), excluding the possibility that the higher activity is caused by trypsin-activated chitin synthase in the soluble fraction. Second, no hyperactivation was observed when trypsin was inhibited before being added to the membranes (Fig. 4, panel 5), showing that there was no residual 
trypsin activity.

Since trypsin activity in the trypsinated soluble fraction has been inhibited prior to adding this mixture to the membranes, the activating factor can only be a part of the soluble S. cerevisiae fraction. Moreover, the need for a protease to trigger the stimulatory effect implies that the activating factor in the soluble fraction is a protein. To test whether this soluble protein could be, like trypsin, a protease, we investigated the effect of a range of protease inhibitors on the activated soluble $S$. cerevisiae fraction. Before addition to the Chs2-containing membranes, the trypsin-activated soluble $S$. cerevisiae fraction was incubated with each of the following protease inhibitors: pefabloc, E-64, leupeptin, benzamidin or pepstatin A. Indeed, the addition of leupeptin, a serine and cysteine protease inhibitor, almost completely abolished the stimulatory effect, while it did not affect the activity of Chs 2 or Chs $2 \Delta \mathrm{N} 222$ by itself (Fig. 5).

Identification and isolation of this yeast protease and genetic experiments as performed by [35] will be necessary to understand the physiological role of this phenomenon. However, some characteristics of the activating protease can already be defined. First, the inhibition of activation by leupeptin shows that the enzyme in question is a serine or cysteine protease. Second, activation was only observed when the soluble $S$. cerevisiae fraction was extracted from cells growing logarithmically, and not when it was extracted from cells growing in a stationary phase. Therefore, all proteases that are expressed constitutively, as for instance the vacuolar proteases, can be ruled out as the activating protease. Moreover, the timing of expression of this protease hints to the in vivo relevance of proteolytic activation of Chs2. The protease expression is during the logarithmic phase, when cells are dividing, which is consistent with the timing of Chs2 activity: the primary septum is synthesized after mitosis has completed [36]. Thus, this protease is expressed during the phase when Chs2 activity would peak.

Interestingly, a very similar type of proteolytic regulation is observed for chitin synthase from M. sexta, where the trypsin-activated serine protease CTLP1 was identified to interact with the chitin synthase [37]. Despite this similarity, the location and function of this insect chitin synthase are completely different to those of Chs2: the enzyme creates a protective matrix that lines the midgut of the larvae [38]. Similar modes of regulation for two chitin synthases from very different species, performing very different functions, suggest that this activation mechanism might be widespread.

\section{Phosphorylation}

Another fast and reversible way of enzyme regulation by post-translational modification is protein phosphorylation. To find out whether phosphorylation influences the activity of Chs2, we submitted $P$. pastoris membranes containing either Chs 2 or Chs $2 \Delta \mathrm{N} 222$ to dephosphorylation by the unspecific calf intestine alkaline phosphatase. Dephosphorylation of membranes containing Chs2, whether trypsin-treated or not, does not significantly affect chitin synthase activity (Fig. 6, panel 3 and 4). Therefore, Chs2 does not appear to contain a phosphorylation site that plays a direct role in catalysis. However, when phosphatase treatment is followed by trypsination, activity is almost completely lost (Fig. 6, panel 5), indicating degradation of the protein. These results show that active Chs 2 does contain one or more phosphorylation sites. These might, as for glycogen phosphorylase [39], be involved in organization and stabilization of the subunit structure of the enzyme. Similar experiments with Chs $2 \Delta \mathrm{N} 222$ show no effect after phosphatase treatment (Fig. 6, panel 5), indicating that the phosphate groups that affect 
protein stability interact with or are located in the N-terminal domain.

Previous knowledge about phosphorylation of Chs2 is summarized in Fig. 1. So far, Ser82 and Ser86 are the only phosphorylation sites that have been identified for wildtype Chs2 [40]. Additionally, Chs2 has been shown to be an in vitro substrate of the cyclin-dependent kinase Cdk1 [29, 30]. To map the phosphorylation sites of Chs2, we analyzed the purified enzyme by mass spectrometry [41, 42]. For this type of analysis, microgram amounts of pure protein are required. The level of Chs 2 expression in $P$. pastoris allowed for purification of sufficient amounts of protein. We were able to solubilize the overexpressed enzyme in Fos-choline-14 detergent, and established an IMAC purification protocol using the $\mathrm{His}_{10}$ affinity tag. This single purification step significantly enriched the Chs 2 content in the protein mixture, yielding $\sim 50 \%$ pure Chs 2 . The enzyme was further separated by SDS/PAGE (Fig. 7a) and could be enriched to 100 $\%$ purity for mapping of phosphorylation sites by mass spectrometry.

LC-MS/MS analysis identified twelve phosphorylation sites (Table 1), all in the $\mathrm{N}$-terminal domain. The localization of the sites is consistent with our dephosphorylation experiments. Whereas Chs 2 is affected by dephosphorylation, Chs $2 \Delta \mathrm{N} 222$, having only one of the twelve sites present, is not. Consequently, we can conclude that dephosphorylation of the N-terminal domain sensitizes the enzyme towards trypsin. Trypsin is a highly unspecific protease, which cleaves a polypeptide chain after almost every exposed positively charged amino acid residue. An elevated sensitivity towards trypsin usually indicates a less compactly folded and thus less stable protein. Dephosphorylation of the N-terminal domain clearly exposes and destabilizes parts of Chs2 that are stable when this domain is phosphorylated or not present at all. This hints at a regulatory function for (de)phosphorylation of the N-terminal domain, as for example an involvement in the short lifetime of the enzyme.

Expression, localization and degradation of Chs2 are cell cycle dependent [15]. The enzyme is mainly expressed during mitosis [13]. It is transported from the endoplasmic reticulum to the mother-bud neck at mitotic exit, to synthesize the primary septum [27]. Finally, after cytokinesis it is proteolytically processed in the vacuole [14]. Such a complex cycle requires tight regulation of activity and stability. If phosphorylation is important for protein stability, the enzyme should be phosphorylated immediately after synthesis, and dephosphorylation could then facilitate rapid degradation of the protein when this becomes necessary.

In this light, it is interesting to note that four phosphorylation sites match the perfect phosphorylation motif $(\mathrm{S} / \mathrm{TP}-\mathrm{x}-\mathrm{K} / \mathrm{R})$ for $\mathrm{Cdk} 1$, a cyclin-dependent kinase that controls many cell cycle events, and that they are all located in the $\mathrm{N}$-terminal domain (Fig. 1). Furthermore, all four sites are observed in our LC-MS/MS experiments. Indeed, Chs 2 has been revealed as an in vitro substrate of Cdk1, with the highest phosphorylation rate when it is complexed with $\mathrm{Clb} 2[29,30]$. We have used the homologous human complex in combination with $\gamma-{ }^{32} \mathrm{P}-\mathrm{ATP}$ and have shown that Chs $2 \Delta \mathrm{N} 222$ is not phosphorylated by this complex while Chs 2 is (Fig. 7b). Thus, Cdk1 phosphorylation by Cdk1 is at the N-terminal domain, which is consistent with the phosphorylation sites observed with MS/MS.

The N-terminal domains of chitin synthases can be quite different, and their regulatory role is uncertain [16]. However, CaChs1, the functional homologue of Chs2 
from $C$. albicans, has an N-terminal domain that is homologous to that of Chs2, and contains three perfect $\mathrm{Cdk} 1$ phosphorylation motifs. Indeed, all $\mathrm{N}$-terminal domains that are homologous to that of Chs2 (UniProtKB primary accession numbers Q6FQN5, A7TEI4, Q6CS65, Q758F2 and Q6BZ46) contain multiple perfect Cdk1 phosphorylation sites, in most cases even in the same position as for Chs2. Therefore, it appears that the Cdk1 phosphorylation sites are a feature of this family of N-terminal domains, strengthening the suggestion of a functional role.

Chs2 is most efficiently phosphorylated when Cdk1 is complexed with Clb2 [30]. As this is an $\mathrm{M}$ phase cyclin, it is active during mitosis, when Chs 2 is synthesized, but not after cytokinesis, when Chs2 is degraded. Cdk1-Clb2 phosphorylates the N-terminal domain of Chs2, and the timing of its activity is correlated with that of Chs2. As tempting as it is to speculate about a possible role for Cdk1 in regulating Chs 2 activity, sitedirected mutagenesis studies will be necessary to confirm whether these specific phosphorylation sites are of importance for the short lifetime of Chs 2 .

Footnotes - The abbreviations used are: Chs, chitin synthase; GlcNAc, $\mathrm{N}$ acetylglucosamine; MGY, minimal glycerol; OD, optical density; MM, minimal methanol; TB, terrific broth; IPTG, isopropyl $\beta$-D-1-thiogalactopyranoside; YPD, yeast extract peptone dextrose; LC, liquid chromatography; MS/MS, tandem mass spectrometry.

Acknowledgements - We are most grateful to Werner Kühlbrandt for his support and for fruitful discussions, to David Parcej for advice on the Pichia expression system, to Qishan Li for support on the mass spectrometry experiments, and to Paolo Lastrico for help with figures. 


\section{References}

1 Cabib, E., Roberts, R. and Bowers, B. (1982) Synthesis of the yeast cell wall and its regulation. Ann. Rev. Biochem. 51, 763-793

2 Shaw, J. A., Mol, P. C., Bowers, B., Silverman, S. J., Valdivieso, M. H., Durán, A. and Cabib, E. (1991) The function of chitin synthases 2 and 3 in the Saccharomyces cerevisiae cell cycle. J. Cell Biol. 114, 111-123

3 Silverman, S. J. (1989) Similar and different domains of chitin synthases 1 and 2 of S. cerevisiae: two isozymes with distinct functions. Yeast 5, 459-467

4 Campbell, J. A., Davies, G. J., Bulone, V. and Henrissat, B. (1997) A classification of nucleotide-diphospho-sugar glycosyltransferases based on amino acid sequence similarities. Biochem. J. 326, 929-939

5 Coutinho, P. M., Deleury, E., Davies, G. J. and Henrissat, B. (2003) An evolving hierarchical family classification for glycosyltransferases. J. Mol. Biol. 328, 307-317

6 Charnock, S. J. and Davies, G. J. (1999) Structure of the nucleotide-diphospho-sugar transferase, SpsA from Bacillus subtilis, in native and nucleotide-complexed forms. Biochemistry 38, 6380-6385

7 Cabib, E., Sburlati, A., Bowers, B. and Silverman, S. J. (1989) Chitin Synthase 1, an auxiliary enzyme for chitin synthesis in Saccharomyces cerevisiae. J. Cell Biol. 108, $1665-1672$

8 Silverman, S. J., Sburlati, A., Slater, M. L. and Cabib, E. (1988) Chitin synthase 2 is essential for septum formation and cell division in Saccharomyces cerevisiae. Proc. Natl. Acad. Sci. USA 85, 4735-4739

9 Bulawa, C. E., Slater, M., Cabib, E., Au-Young, J., Sburlati, A., Adair, W. L. and Robbins, P. W. (1986) The S. cerevisiae structural gene for chitin synthase is not required for chitin synthesis in vivo. Cell 46, 213-225

10 Valdivieso, M. H., Mol, P. C., Shaw, J. A., Cabib, E. and Durán, A. (1991) CAL1, a gene required for activity of chitin synthase 3 in Saccharomyces cerevisiae. J. Cell Biol. 114, 101-109

11 Nagahashi, S., Sudoh, M., Ono, N., Sawada, R., Yamaguchi, E., Uchida, Y., Mio, T., Takagi, M., Arisawa, M and Yamada-Okabe, H. (1995) Characterization of chitin synthase 2 of Saccharomyces cerevisiae. Implication of two highly conserved domains as possible catalytic sites. J. Biol. Chem. 270, 13961-13967

12 Munro, C. A., Winter, K., Buchan, A., Henry, K., Becker, J. M., Brown, A. J. P., Bulawa, C. E. and Gow, N. A. R. (2001) Chs1 of Candida albicans is an essential chitin synthase required for synthesis of the septum and for cell integrity. Mol. Microbiol. 39, 1414-1426

13 Choi, W.-J., Santos, B., Durán, A. and Cabib, E. (1994) Are yeast chitin synthases regulated at the transcriptional or the posttranslational level? Mol. Cell. Biol. 14, 7685-7694

14 Chuang, J. S. and Schekman, R. W. (1996) Differential trafficking and timed localization of two chitin synthase proteins, Chs2p and Chs3p. J. Cell Biol. 135, 597610

15 Roncero, C. (2002) The genetic complexity of chitin synthesis in fungi. Curr. Genet. 41, 367-378

16 Ford, R. A., Shaw, J. A. and Cabib, E. (1996) Yeast chitin synthases 1 and 2 consist of a non-homologous and dispensable N-terminal region and of a homologous moiety essential for function. Mol. Gen. Genet. 252, 420-428

17 André, N., Cherouati, N., Prual, C., Steffan, T., Zeder-Lutz, G., Magnin, T., Pattus, F., Michel, H., Wagner, R. and Reinhart, C. (2006) Enhancing functional production 
of G protein-coupled receptors in Pichia pastoris to levels required for structural studies via a single expression screen. Prot. Science 15, 1115-1126

18 Sburlati, A. and Cabib, E. (1986) Chitin synthetase 2, a presumptive participant in septum formation in Saccharomyces cerevisiae. J. Biol. Chem. 261, 15147-15152

19 Au-Young, J. and Robbins, P. W. (1990) Isolation of a chitin synthase gene (CHS1) from Candida albicans by expression in Saccharomyces cerevisiae. Mol. Microbiol. 4, 197-207

20 Fähnrich, M. and Ahlers, J. (1981) Improved assay and mechanism of the reaction catalyzed by the chitin synthase from Saccharomyces cerevisiae. Eur. J. Biochem. 121, 113-118

21 Sudoh, M., Yamazaki, T., Masubuchi, K., Taniguchi, M., Shimma, N., Arisawa, M. and Yamada-Okabe, H. (2000) Identification of a novel inhibitor specific to the fungal chitin synthase - Inhibition of chitin synthase 1 arrests the cell growth, but inhibition of chitin synthase 1 and 2 is lethal in the pathogenic fungus Candida albicans. J. Biol. Chem. 275, 32901-32905

22 Uchida, Y., Shimmi, O., Sudoh, M., Arisawa, M. and Yamada-Okabe, H. (1996) Characterization of chitin synthase 2 of saccharomyces cerevisiae II: both full size and processed enzymes are active for chitin synthesis. J. Biochem. 119, 659-666

23 Persson, K., Ly, H. D., Dieckelmann, M., Wakarchuk, W. W., Withers, S. G. and Strynadka, N. C. J. (2001) Crystal structure of the retaining galactosyltransferase LgtC from Neisseria meningitidis in complex with donor and acceptor sugar analogs. Nature Struct. Biol. 8, 166-175

24 Choi, W.-J. and Cabib, E. (1994) The use of divalent cations and $\mathrm{pH}$ for the determination of specific yeast chitin synthetases. Anal. Biochem. 219, 368-372

25 Schmidt, M., Bowers, B., Varma, A., Roh, D.H. and Cabib, E. (2002) In budding yeast, contraction of the actomyosin ring and formation of the primary septum at cytokinesis depend on each other. J. Cell Sci. 115, 293-302

26 Tolliday, N., Pitcher, M. and Li, R. (2003) Direct evidence for a critical role of myosin II in budding yeast cytokinesis and the evolvability of new cytokinetic mechanisms in the absence of myosin II. Mol. Biol. Cell 14, 798-809

27 Zhang, G., Kashimshetty, R., Ng, K. E., Tan, H. B. and Yeong, F. M. (2006) Exit from mitosis triggers Chs $2 \mathrm{p}$ transport from the endoplasmic reticulum to motherdaughter neck via the secretory pathway in budding yeast. J. Cell Biol. 174, 207-220

28 Roh, D.-H., Bowers, B., Schmidt, M. and Cabib, E. (2002) The septation apparatus, an autonomous system in budding yeast. Mol. Biol. Cell 13, 2747-2759

29 Ubersax, J. A., Woodbury, E. L., Quang, P. N., Paraz, M., Blethrow, J. D., Shah, K., Shokat, K. M. and Morgan, D. O. (2003) Targets of the cyclin-dependent kinase Cdk1. Nature 425, 859-864

30 Loog, M. and Morgan, D. O. (2005) Cyclin specificity in the phosphorylation of cyclin-dependent kinase substrates. Nature 434, 104-108

31 Cabib, E. and Farkas, V. (1971) The control of morphogenesis: enzymatic mechanism for initiation of septum formation in yeast. Proc. Natl. Acad. Sci. USA 68, 2052-2056

32 Zimoch, L., Hogenkamp, D. G., Kramer, K. J., Muthukrishnan, S. and Merzendorfer, H. (2005) Regulation of chitin synthesis in the larval midgut of Manduca sexta. Insect Biochem. Mol. Biol. 35, 515-527

33 Ulane, R. E. and Cabib, E. (1976) The activating system of chitin synthetase from Saccharomyces cerevisiae - purification and properties of activating factor. J. Biol. Chem. 251, 3367-3374 
34 Zubenko, G. S., Mitchell, A. P. and Jones, E. W. (1979) Septum formation, cell division, and sporulation in mutants of yeast deficient in proteinase B. Proc. Natl. Acad. Sci. USA 76, 2395-2399

35 Silverman, S. J., Shaw, J. A. and Cabib, E. (1991) Proteinase B is, indeed, not required for chitin synthetase 1 function in Saccharomyces cerevisiae. Biochem. Biophys. Res. Comm. 174, 204-210

36 Cabib, E. (2004) The septation apparatus, a chitin-requiring machine in budding yeast. Arch. Biochem. Biophys. 426, 201-207

37 Broehan, G., Zimoch, L., Wessels, A., Ertas, B. and Merzendorfer, H. (2007) A chymotrypsin-like serine protease interacts with the chitin synthase from the midgut of the tobacco hornworm. J. Exp. Biol. 210, 3636-3643

38 Merzendorfer, H. (2006) Insect chitin synthases: a review. J. Comp. Physiol. B 176, $1-15$

39 Johnson, L. N. (1992) Glycogen phosphorylase: control by phosphorylation and allosteric effectors. FASEB J. 6, 2274-2282

40 Ficarro, S. B., McCleland, M. L., Stukenberg, P. T., Burke, D. J., Ross, M. M., Shabanowitz, J., Hunt, D. F. and White, F. M. (2002) Phosphoproteome analysis by mass spectrometry and its application to Saccharomyces cerevisiae. Nat. Biotechnol. 20, 301-305

41 Gafken, P. R. and Lampe, P. D. (2006) Methodologies for characterizing phosphoproteins by mass spectrometry. Cell Commun. Adhes. 13, 249-262

42 Zheng, X.-D., Lee, R. T. H., Wang, Y.-M., Lin, Q. S. and Wang, Y. (2007) Phosphorylation of Rga2, a Cdc42 GAP, by CDK/Hgc1 is crucial for Candida albicans hyphal growth. EMBO J. 26, 3760-3769 
Table 1. Mass spectrometry identification of phosphorylation sites on Chs2

4 NPFMVEPS*NGSPNR 17

4 NPFMVEPSNGS*PNR 17

36 WANPSEESLEDSYDQSNVFQGLPAS*PSR 63

64 AALRY $\underline{S P D R R} 73$

93 YAANLQES*PKR 103

121 DNADLPVDPY*HLSPQQQPSNNLFGSGR 147

121 DNADLPVDPYHLS*PQQQPSNNLFGSGR 147

121 DNADLPVDPYHLSPQQQPSNNLFGS*GR 147

155 YTMSTTSTTAPSLAEADDEKEK 176

177 YLTS*TTSYDDQSTIFSADTFNETK 200

177 YLTSTTSYDDQSTIFS*ADTFNETK 200

254 RNSPEFTEMR 263

The table lists the phospho-peptides that were identified based on neutral loss of a mass of 98 and three continuous ion series. The residues denoted with an asterisk (*) are phosphorylated residues identified without ambiguity. The underlined residues are sites identified with neutral loss of a mass of 98 and only two continuous ion series. Sequence coverage was $56 \%$. 


\section{Figure legends}

Fig. 1. Schematic drawing of the domain organisation of Chs2. The N-terminal soluble domain and the central catalytic domain are located in the cytoplasm; the hydrophobic Cterminal domain is anchored in the plasma membrane. Shaded circles indicate the positions of observed phosphorylation sites [40], clear circles show those of the consensus phosphorylation sequences for cyclin-dependent kinase 1 . Residue 222, the end of the region that is deleted in the Chs $2 \Delta \mathrm{N} 222$ mutant, is indicated by a cross.

Fig. 2. Western blot analysis of membranes shows that in both expression systems the recombinant proteins were integrated into the membrane. Each protein migrates according to its sequence-based predicted molecular weight, and to the same level when expressed in yeast or bacteria, which implies that both are not glycosylated in P. pastoris. The His-tagged proteins were probed with monoclonal anti-poly-histidine antibody and visualized with alkaline phosphatase-conjugated secondary antibody. Per lane: M) Marker in $\mathrm{kDa}, \mathbf{1}) \mathrm{Chs} 2(115 \mathrm{kDa})$ in P. pastoris, 2) Chs $2 \Delta \mathrm{N} 222(90 \mathrm{kDa})$ in P. pastoris 3) Chs 2 in E. coli, 4) Chs $2 \Delta \mathrm{N} 222$ in E. coli.

Fig. 3. Biochemical characterization of $P$. pastoris-expressed Chs 2 and Chs $2 \Delta \mathrm{N} 222$ shows identical enzymatic properties as compared to the wild-type protein. Black and light-grey bars show the activities of Chs2 and Chs2 $\triangle$ N222, respectively. Dark-grey bars show background activity of native chitin synthases of $P$. pastoris. a. The dependence of protein activity on $\mathrm{pH}$, in the presence of $5 \mathrm{mM} \mathrm{MnCl}$. To ascertain that all differences measured were due only to $\mathrm{pH}$, for each experiment the same buffer mixture $(30 \mathrm{mM}$ HEPES, $30 \mathrm{mM}$ MES and $30 \mathrm{mM}$ TAPS) was used. b. The effect of cations on protein activity, assayed at $\mathrm{pH} 7.5$. Each bar comprises two independent sets of three experiments $(\mathrm{n}=6)$.

Fig. 4. Hyperactivation of P. pastoris-expressed Chs2 (black) and Chs $2 \Delta \mathrm{N} 222$ (grey) by trypsin and/or activated soluble fraction of $S$. cerevisiae. Activities are shown relative to their corresponding 1) base activities (non-treated membranes, 6.0 and $5.5 \mathrm{nmol} \mathrm{GlcNAc}$ incorporated for Chs 2 and Chs $2 \Delta \mathrm{N} 222$, respectively, each set to 100\%). 2) Activities of membranes in the presence of soluble $S$. cerevisiae fraction, 3) activities of membranes in the presence of trypsin-activated soluble $S$. cerevisiae fraction, 4) activities of membranes in the presence of inhibited trypsin, 5) activities of trypsin-treated membranes, 6) activity of trypsin-activated soluble S. cerevisiae fraction by itself. Each bar comprises two independent sets of three experiments $(n=6)$.

Fig. 5. Activation of $P$. pastoris-expressed Chs 2 and Chs $2 \Delta \mathrm{N} 222$ by the $S$. cerevisiae soluble fraction is inhibited by leupeptin. Activity of Chs2 (black) and Chs $2 \Delta$ N222 (grey) is shown relative to 1) base activity (non-treated membranes, set to 100\%). 2) Membranes treated with activated soluble $S$. cerevisiae fraction, 3) activated soluble $S$. cerevisiae fraction inhibited by $400 \mu \mathrm{M}$ leupeptin before addition to membranes, 4) membranes treated with $400 \mu \mathrm{M}$ leupeptin. Each bar comprises two independent sets of three experiments $(\mathrm{n}=6)$.

Fig. 6. Phosphatase treatment of P. pastoris-expressed Chs 2 (black) and Chs $2 \Delta \mathrm{N} 222$ (grey). Activities are shown relative to their corresponding 1) base activities (non-treated membranes, 6.0 and $5.5 \mathrm{nmol}$ GlcNAc incorporated for Chs2 and Chs $2 \Delta \mathrm{N} 222$, 
respectively, each set to $100 \%$ ). 2) Activities of trypsin-treated membranes, 3) activities of membranes treated with alkaline phosphatase, 4) activities of membranes treated with trypsin, followed by alkaline phosphatase 5) activities of membranes treated with alkaline phoshphatase, followed by trypsin. Each bar comprises two independent sets of three experiments $(\mathrm{n}=6)$.

Fig. 7. Phosphorylation analysis. a. SDS/PAGE analysis of partially purified Chs2. Left lane: marker in $\mathrm{kDa}$, right lane: Chs $2(115 \mathrm{kDa})$ partially purified by IMAC. The single purification step followed by SDS/PAGE allowed for the isolation of pure Chs 2 for LCMS/MS phosphorylation site mapping. b. Autoradiography analysis of an SDS/PAGE gel from $P$. pastoris membranes containing overexpressed Chs 2 or Chs $2 \Delta \mathrm{N} 222$ after treatment with Cdc2-cyclin B plus $\gamma{ }^{32} \mathrm{P}$-ATP. Per lane: M) Marker in kDa, 1) Membranes containing overexpressed Chs 2 show a band at the molecular weight of the recombinant protein 2) Membranes containing overexpressed Chs $2 \Delta \mathrm{N} 222$ do not show a signal at the molecular weight of the recombinant protein. 
Fig. 1

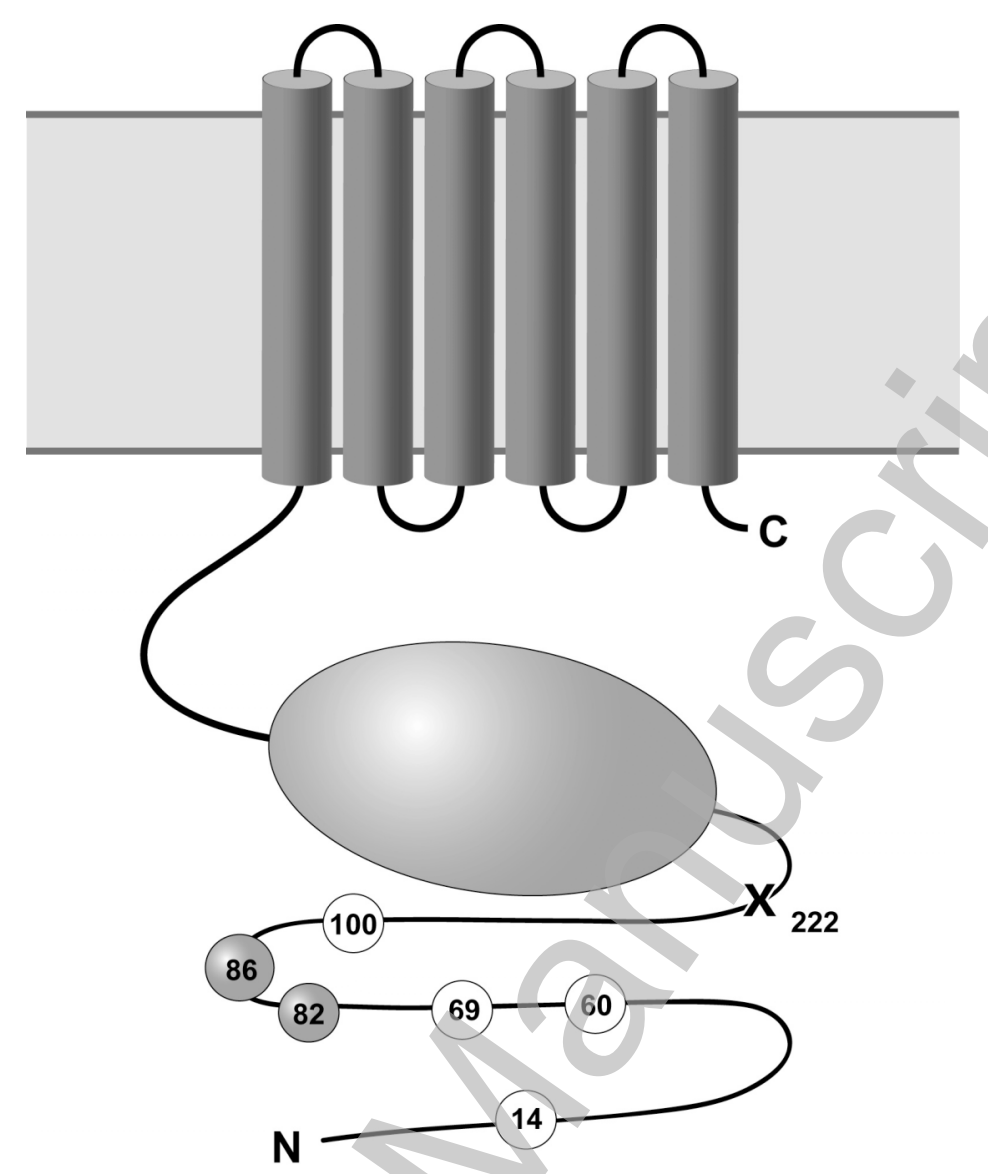


Fig. 2

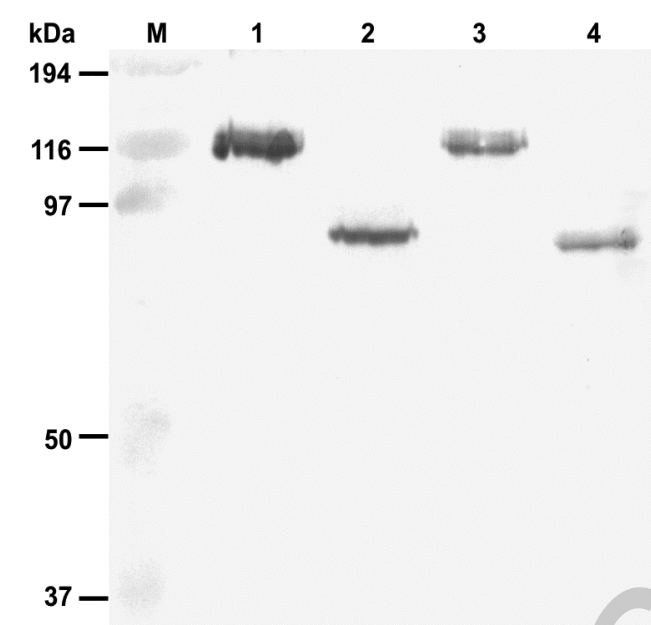


Fig. 3a

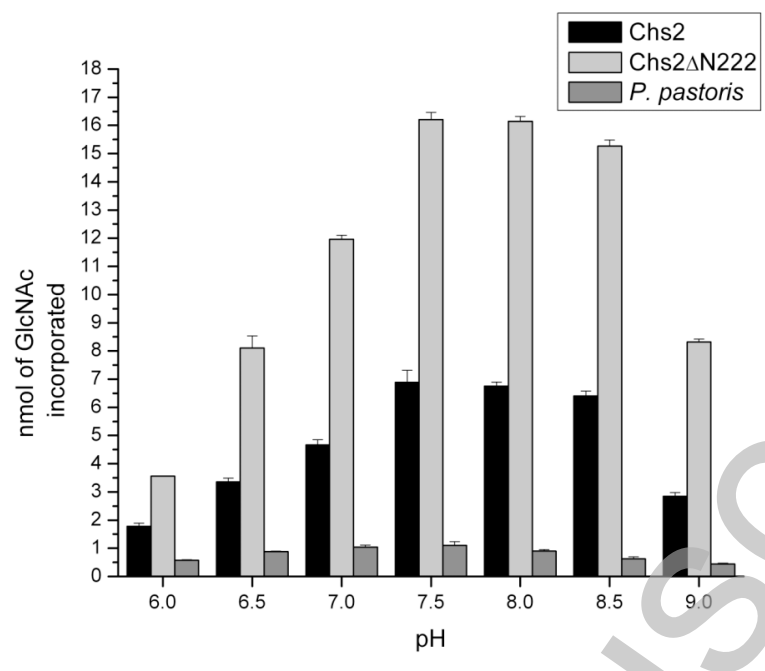

3b 
Fig. 4

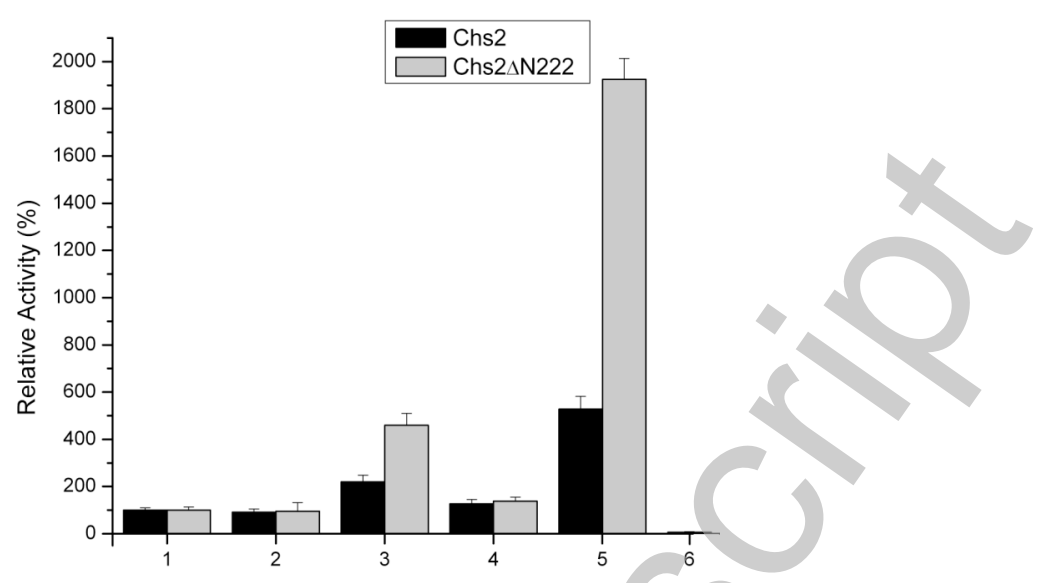


Fig. 5

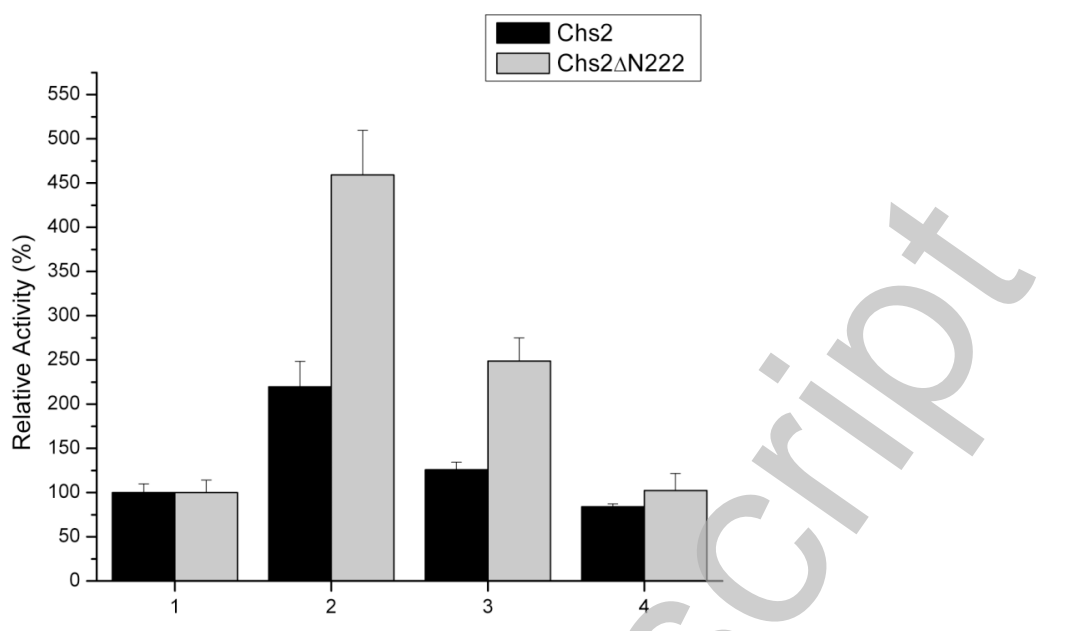


Fig. 6

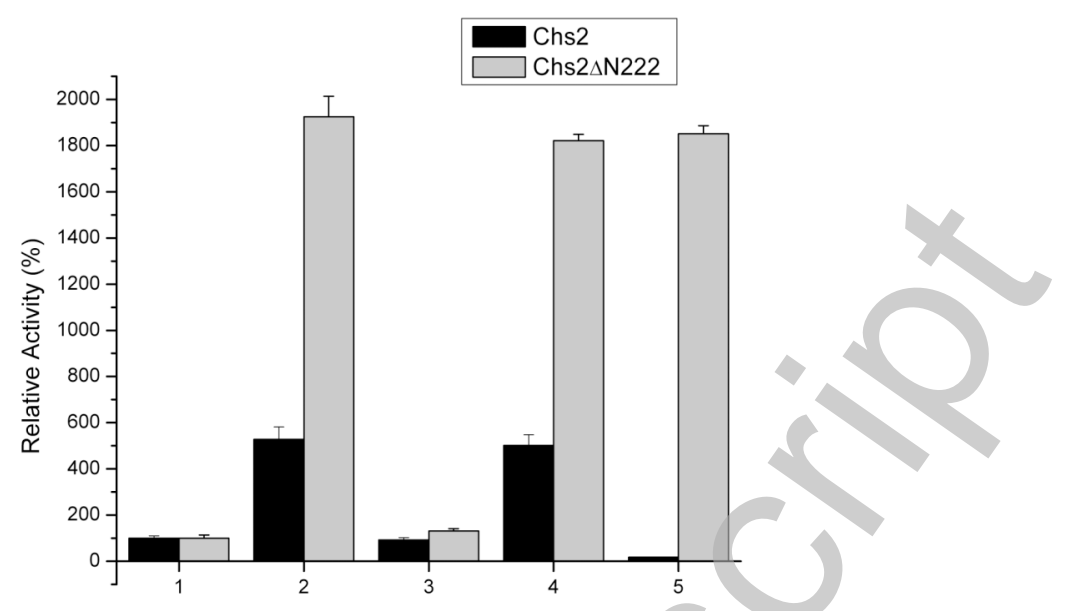


Fig. 7a

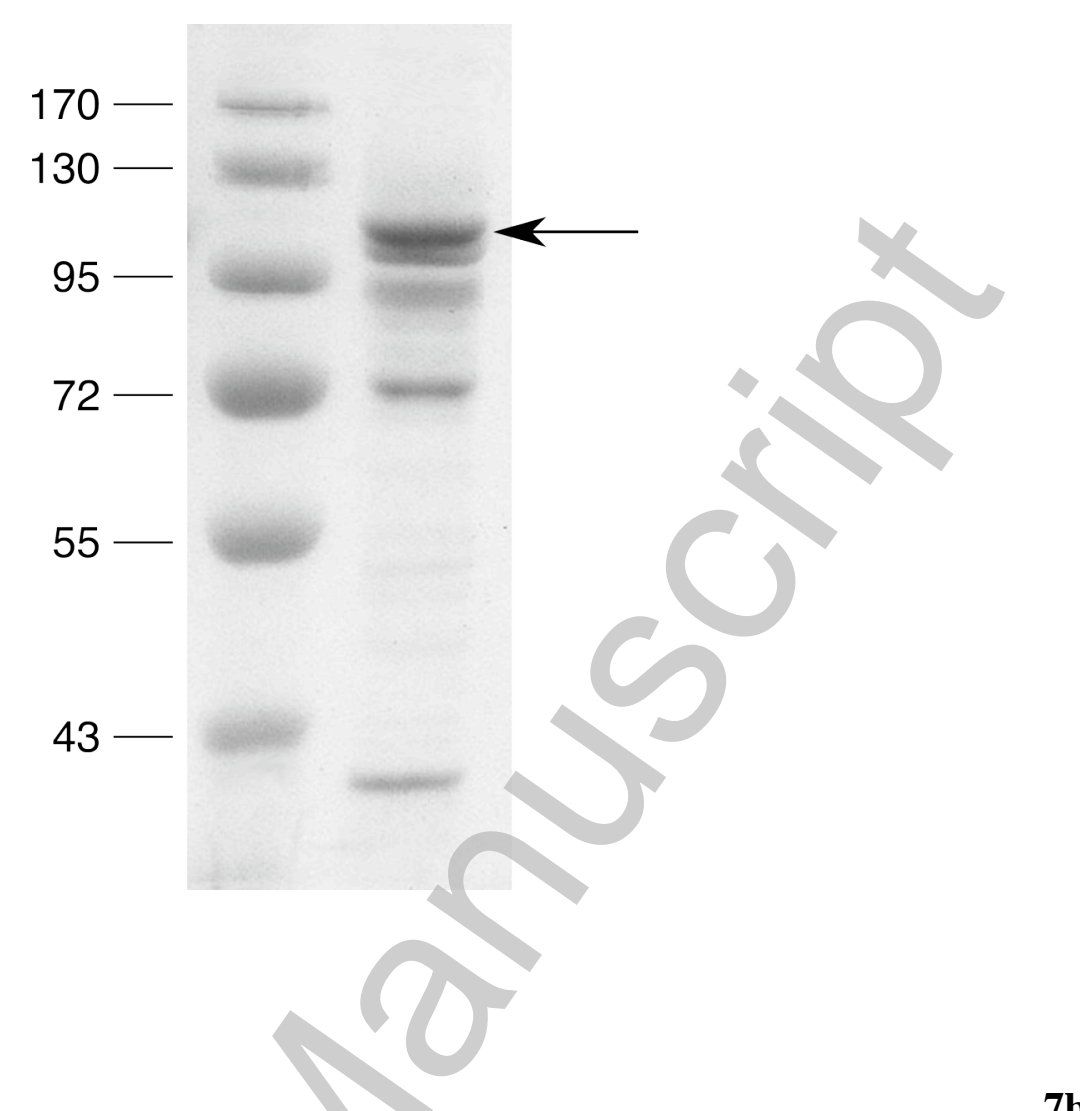

$7 \mathbf{b}$

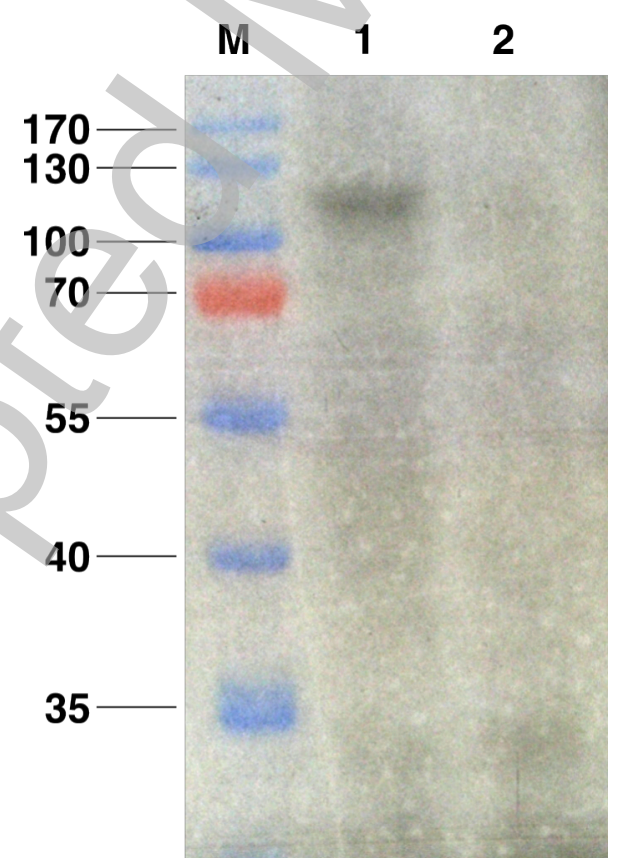

